\title{
Cold Helium Pressurization for Liquid Oxygen / Liquid Methane Propulsion Systems: Fully-Integrated Initial Hot-Fire Test Results
}

\author{
R. L. Morehead, AIAA Member \\ M. J. Atwell, AIAA Member \\ J.C. Melcher, AIAA Senior Member \\ E.A. Hurlbert, AIAA Member \\ NASA Johnson Space Center, Houston TX, 77058, United States
}

\begin{abstract}
A prototype cold helium active pressurization system was incorporated into an existing liquid oxygen (LOX) / liquid methane (LCH4) prototype planetary lander and hot-fire tested to collect vehicle-level performance data. Results from this hot-fire test series were used to validate integrated models of the vehicle helium and propulsion systems and demonstrate system effectiveness for a throttling lander. Pressurization systems vary greatly in complexity and efficiency between vehicles, so a pressurization performance metric was also developed as a means to compare different active pressurization schemes. This implementation of an active repress system is an initial sizing draft. Refined implementations will be tested in the future, improving the general knowledge base for a cryogenic lander-based cold helium system.
\end{abstract}

\section{Nomenclature}

$\begin{array}{ll}C F_{c} & \text { Cumulative Collapse Factor } \\ C F_{i} & \text { Instantaneous Collapse Factor } \\ \varepsilon & \text { Nozzle Area Ratio } \\ \dot{m} & \text { Mass flow rate, lbm/sec } \\ \Delta \mathrm{P} & \text { Difference between two pressure states, psid } \\ \Delta \mathrm{T} & \text { Helium temperature change in HEX, deg F } \\ \mathrm{Pc} & \text { Chamber pressure } \\ \mathrm{P}-\mathrm{V}-\mathrm{T} & \text { Pressure, Volume, Temperature } \\ \dot{v} & \text { volumetric flowrate, } \mathrm{ft}^{3} / \mathrm{sec} \\ -\mathrm{Y} & \text { One of two propellant tanks on the vehicle } \mathrm{Y} \text { axis } \\ -\mathrm{Z} & \text { One of two propellant tanks on the vehicle } \mathrm{Z} \text { axis }\end{array}$

$\begin{array}{ll}\begin{array}{l}\text { Acronyms } \\ \text { APU }\end{array} & \begin{array}{l}\text { Avionics and Power Unit } \\ \text { British Thermal Unit } \\ \text { BTU }\end{array} \\ \text { CFD } & \text { Computational Fluid Dynamics } \\ \text { COPV } & \text { Gaseous Nitrogen } \\ \text { GN2 } & \text { Heat EXchanger } \\ \text { HEX } & \text { NASA Johnson Space Center } \\ \text { JSC } & \text { Liquid Methane } \\ \text { LCH4 } & \text { Low Earth Orbit } \\ \text { LEO } & \text { Liquid Nitrogen } \\ \text { LN2 } & \text { Liquid Oxygen } \\ \text { LOX } & \text { Propellant tank level sensor } \\ \text { LS } & \text { NASA Stennis Space Center } \\ \text { SSC } & \end{array}$




\section{Introduction}

For pressure-fed propulsion systems, helium stored at cryogenic gaseous conditions and then used as a heated tank pressurant provides a substantial density advantage vs. ambient temperature storage. This translates into reduced helium system dry mass, resulting in substantial payload increases in lander applications. This degree of mass reduction also enables pressure-fed propulsion systems for human-rated Mars ascent vehicle designs.

Similar systems have been employed in the past. A relevant lander application is the Apollo era Lunar Module ${ }^{1}$. In this design, helium was loaded as a liquid (-452F) on the launch pad and allowed to warm on its way to the moon, arriving there at $-400 \mathrm{~F}$ ( 10BTU/hr or 3 Watts heat leak). This helium was warmed via a standalone fuel-tohelium heat exchanger to $35 \mathrm{~F}$ and then injected into the hypergolic propellant tanks. Since hypergolic fuel is stored at near room temperature conditions, the pressurization efficiency would have been very high. The demonstrated weight savings for this system was $280 \mathrm{lb}$, or half the weight of the lunar rover.

Other examples include the Apollo-era Saturn V $3^{\text {rd }}$ stage vehicle with a dedicated LOXhydrogen helium heater for in-flight repressurization ${ }^{2}$; the SpaceX Falcon 1 second stage, with a nozzle mounted heat exchanger on the Kestrel engine; and the Falcon 9 vehicle, with helium tanks submerged in the LOX tank and helium heat exchangers in the main engine gas generator exhaust system. The helium system on the Falcon 1 second stage is the most similar application to the small lander-type system tested in this experiment, utilizing a high temperature HEX and one cryogenic propellant (LOX) on a relatively small vehicle. The present experiment results suggest that, when vehicles reach this size, the latent heat in the helium pressurization system (especially for a booster application) and relatively large ullage volumes make the pressurization efficiencies very high, and the pressurization system implementation straightforward with larger margins.

The stressing variables of the potential LOX/methane lander application are two cryogenic propellants / ullage vapors, deep throttling main engine, small size (tanks and pressurization systems), and potentially very cold initial conditions due to long coast times from Earth. Additional complex variables that could be employed are a high temperature source for helium heating (main engine nozzle), and the cooling/thermal maintenance solution for the cold helium storage. Volume-constrained upper stages/landers may not have the option to submerge the helium tanks in the propellant tanks and therefore may require standalone prelaunch cooling and storage for those tanks.

To quantify performance benefits and limitations for the lander-based cold helium system application, a basic cold helium active pressurization system was added to an existing LOX/Methane prototype lander and hotfire tested at NASA Johnson Space Center (JSC) in September, 2015 (Figure 1). The former Morpheus Project ${ }^{3}$ hardware, no longer needed for flight testing, provides an ideal platform for vehicle-level testing. The vehicle test bed provides an operational test platform complete with propellant tanks, feedsystems, a throttling main engine, reaction control system (RCS), and avionics for control and data 
acquisition. The previous ground and flight testing of the Morpheus test bed in 2013-2014 was conducted without an active pressurization system ${ }^{4}$ (i.e. in blowdown mode).

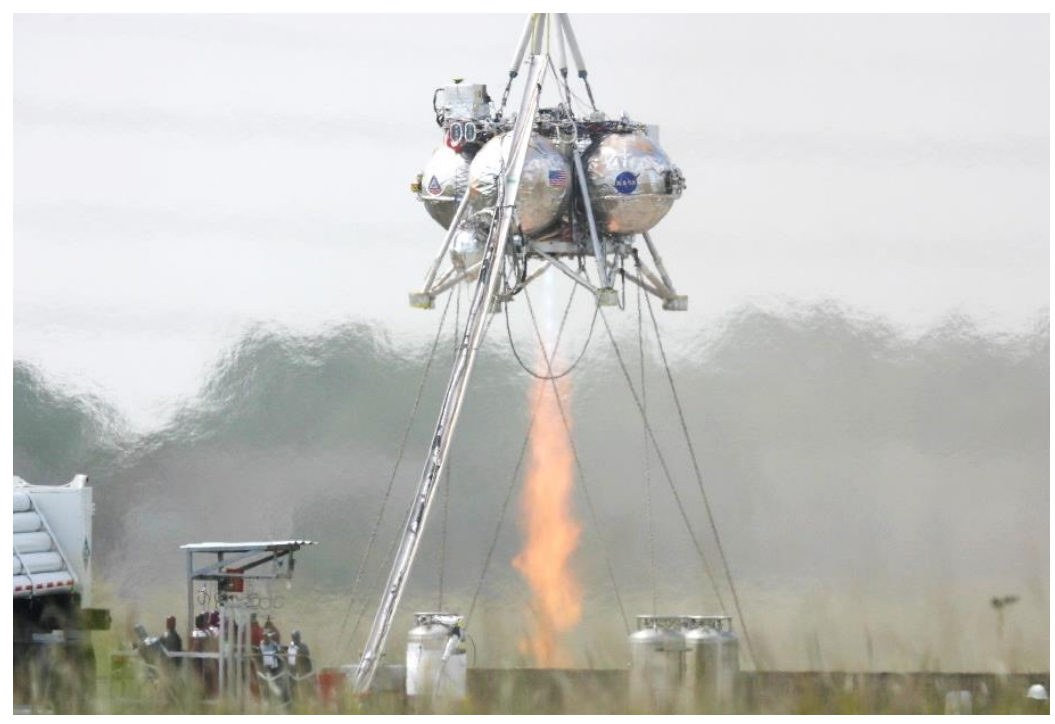

Figure 1: Hot-Fire Testing of the Cold Helium

Pressurization system integrated with vehicle test bed

Fifteen hotfire tests were performed on the integrated vehicle with the cold helium system, demonstrating stable pressurization and acceptable heat exchanger temperatures across a 5:1 throttle range. Performance data was collected at many locations within the integrated system, providing model validation data useable for future vehicle designs.

Thermal vacuum hotfire testing of this vehicle is planned in the upcoming year. This testing, funded for a different purpose, will have the secondary benefit of expanding the test cases for this cold helium system to include deep-space temperature prechill of the vehicle and full propellant tank initial condition cases.

\section{Active Pressurization System Design}

The active pressurization system installed on the test bed consists of a helium storage vessel (gas phase only, stored at roughly LN2 temperatures), an engine nozzle-mounted heat exchanger (HEX), and a regulator/isolation panel with parallel systems for the LOX and Methane propellants. The output of this repress system interfaced with the vehicle helium system immediately upstream of the four propellant tanks. This particular implementation scheme utilizes a high pressure HEX operating at storage tank pressure. The high pressure HEX design strategy is the preferred system-level solution for a throttling lander, offering several distinct advantages as discussed later in the paper.

\section{Helium Storage Vessel}

A commercially-available, 4500 psi cryogenic 19" diameter spherical aluminum lined composite overwrap pressure vessel (COPV) built by ARDE, Inc was utilized for helium pressurant storage (Figure 2). This COPV was procured and tested as part of a family of 
vessels in $2007^{5}$, including cycle and burst testing (>10,500psi). This tank was also used in 2010 to test tank chill strategies and heat transfer properties in a thermal vacuum chamber at JSC, including cold-sinking the COPV to an LN2 tank using graphite straps to maintain helium tank temperature ${ }^{6}$.

In the current pressurization system, the COPV was mounted vertically next to the vehicle's lower frame and attached to the vehicle via swivel bearings attached to the upper and lower tank bosses to minimize thermally induced torque and compressive loads into the COPV. A ground-supplied LN2 active cooling system was installed as a jacket surrounding the helium COPV, focusing the cooling effort on the upper tank aluminum boss and partially exposed liner. Helium was loaded into the COPV at $3600 \mathrm{psig}$ and cooled in situ to $-300{ }^{\circ} \mathrm{F}$. The COPV top boss acted as the inlet and outlet of the tank, with insulated outlet tubing plumbed directly into the helium heat exchanger. In this configuration, the COPV, heat exchanger, and vehicle plumbing up to the high pressure regulator panel were all pressurized to the same magnitude.

It was found during the testing in 2010 that heat in the helium gas could be removed from the COPV more quickly and efficiently through direct cooling of the tank boss rather than broad area cooling of the composite overwrap. For this series of tests, LN2 was sprayed onto the exposed aluminum at the top of the tank and allowed to flow down the exterior surface of the tank under a mylar jacket. An aerogel-based insulation blanket enclosed the COPV/LN2 mylar cooling jacket, and GN2/LN2 was allowed to exit the bottom of the jacket onto the ground. A closed loop cooling scheme was used to maintain tank cooling and reduce wasting LN2.

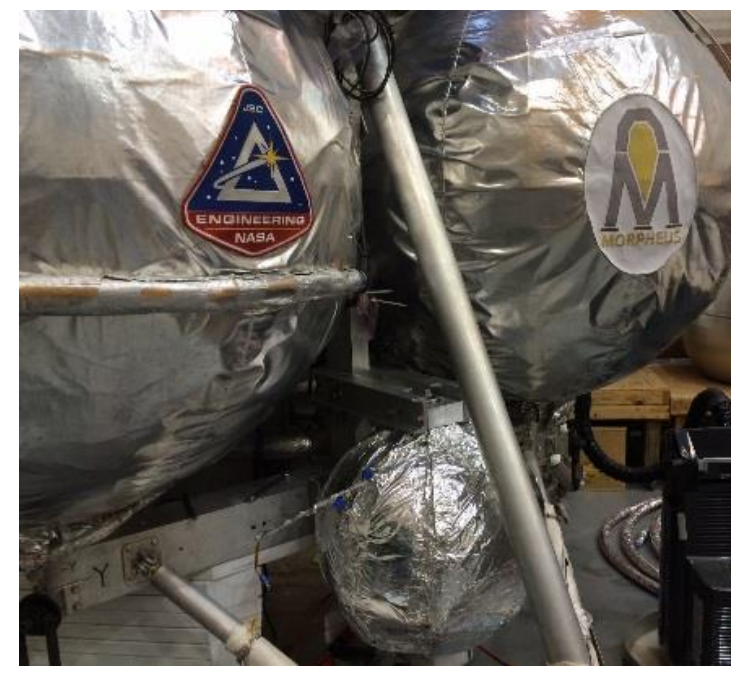

Figure 2: Helium COPV with LN2 thermal shroud and aerogel-based insulation installed on the vehicle test bed under the landing gear 


\section{Helium Heat Exchanger}

A heat exchanger (HEX) mounted on the nozzle exit plane of the vehicle main engine provided the heat necessary to warm the cryogenic helium gas for use as a propellant tank pressurant. The main engine used for testing was a 2,000 lbf sea-level LOX / LCH4 thruster with 5:1 throttling and an ablative combustion chamber built in $2014^{7}$. This engine is appropriately sized for a low-gravity application of a spacecraft the size of Morpheus.

The Inconel HEX was designed specifically for this application with JSC in-house system design tools, using a combination of engine test data and analysis. Nozzle heat flux was measured via a series of engine test firings at NASA Stennis Space Center (SSC), utilizing an additively manufactured axial channel water calorimeter sections installed at the injector/chamber interface and the engine nozzle exit plane (Figure 3). These test results provided design heat flux data across the 5:1 throttling range of the thruster, indicating the following heat flux at the nozzle exit: $1.70 \mathrm{BTU} / \mathrm{in}^{2}$-s at maximum throttle and $0.35 \mathrm{BTU} / \mathrm{in}^{2}$-s at minimum throttle (Figure 4).

EASY5 was utilized to model the entire pressurization system and develop a requirement for heat load into the helium. An in-house MATLAB sizing tool was then developed to quickly iterate on different design parameters and operating conditions. Detailed finite element analysis was then performed for steady-state

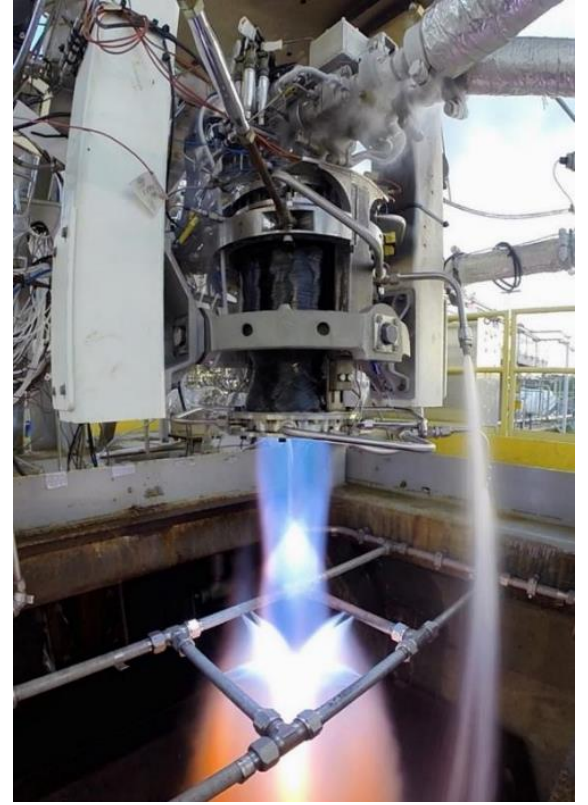

Figure 3: Hotfire testing of the 2,000 lbf thruster on the SSC E-3 test stand using two water calorimeter heat exchangers thermal, stress, and also transient thermal design cases. The minimum design safety factor for off-nominal transient operation was 3.7. One of the largest variables in the design of the heat exchanger was determining the correct helium mass flow rate, which is highly dependent on the rate at which heat transfer inside the propellant tank causes ullage collapse. In order to bound the maximum flow rate for a given throttle setting, conservative natural and mixed convection calculations were performed to determine an approximate upper limit for heat transfer between the entering pressurant and tank walls and the liquid surface. ${ }^{8}$

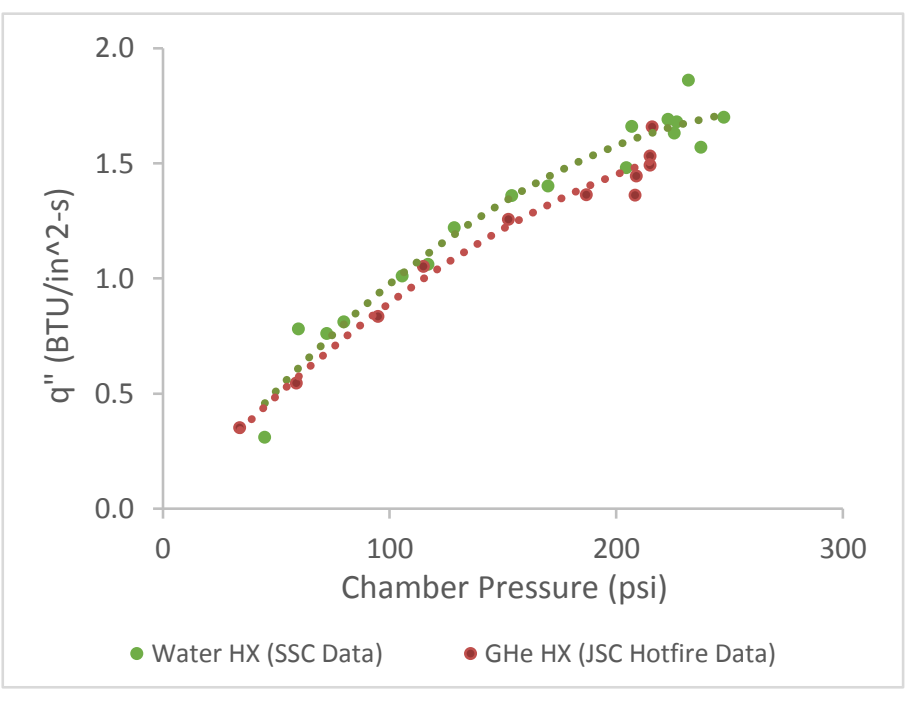

Figure 4: Heat flux data from water calorimeter and helium heat exchanger hotfire testing 


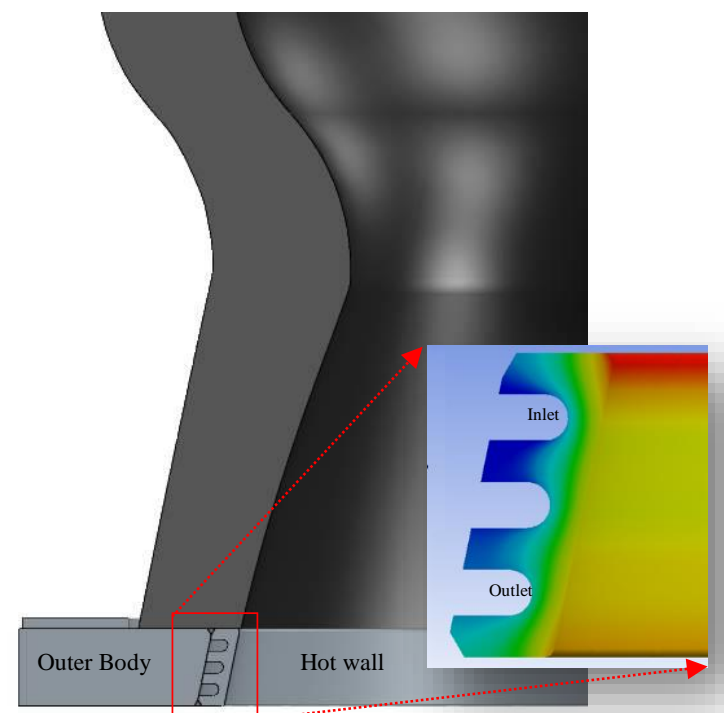

Figure 5: Cross sectional design of HEX with inset of expected temperature distribution

The HEX was manufactured as two nesting disks of Inconel 718 with traditional machining practices followed by final assembly using an interference fit and closeout welding (Figure 5). The heat exchanger consists of a single circumferential channel with three passes, and the conical interior hot wall surface increases the nozzle area ratio from 3.1 to 3.25. The heat flux from the HEX hotwall surface component was predicted to dwarf the latent heat in the large outer body component of the HEX, so the outer diameter of the HEX was oversized to simplify mounting. A backup unit with identical construction was sectioned using a wire EDM, and no gaps were observed between the two middle unrestrained ribs of the inner HEX wall and the smooth outer HEX wall. Under operational thermal/stress conditions, the compressive load on these ribs increases (thermal expansion overrides the high HEX gas pressure in all scenarios) therefore no intra-channel leakage was expected.

The HEX was held in place at the nozzle exit using steel structure and a high temperature ceramic putty at the bondline (Figure 6). The axial interface between the ablative surface and HEX hot wall was smooth and even (no step). The nozzle exit pressure ranges above and below atmospheric pressure with throttle level changes but the delta pressure across the nozzle/HEX bondline was not predicted to be high enough to warrant a complex bondline seal. Leakage across this joint was not observed during testing or posttest inspections.

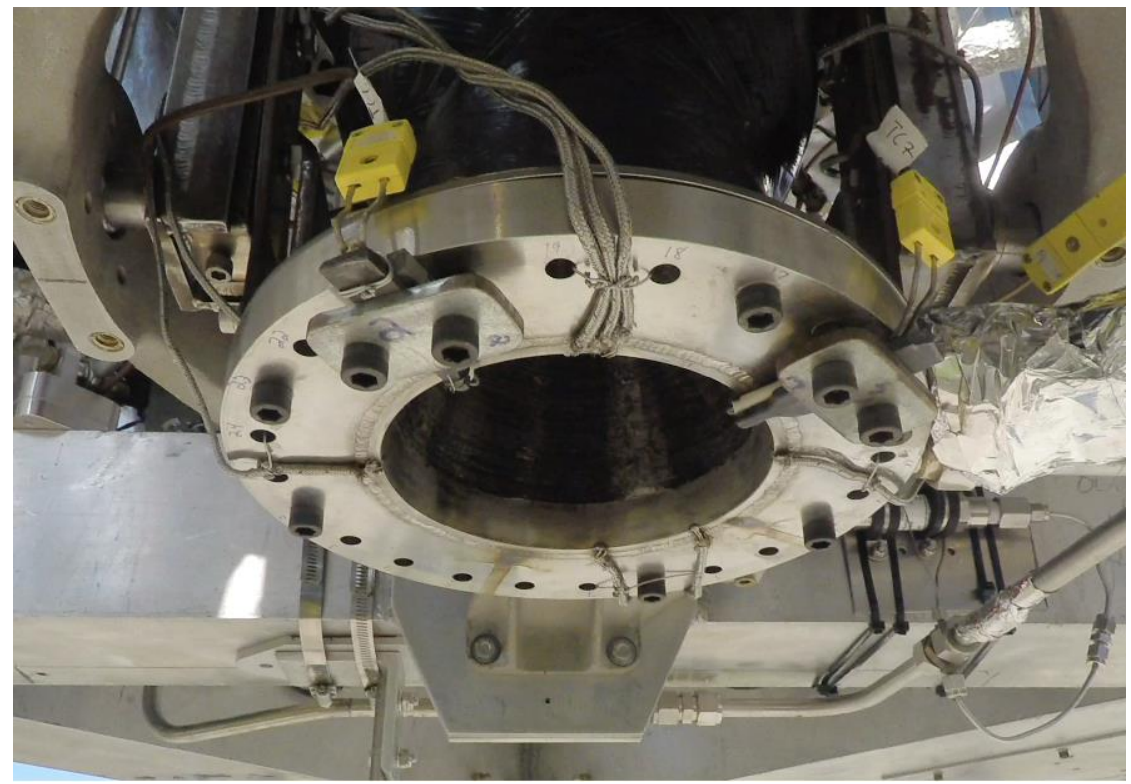

Figure 6: Helium heat exchanger (HEX) installed on main engine nozzle exit. Bottom lip hotwall and two plume boundary layer thermocouples are visible 


\section{Pneumatic Regulation and Isolation}

Pressurant control and regulation was accomplished using available pneumatic components from the Space Shuttle main propulsion helium system and other production launch vehicles (Figure 5). These components, although reliable and of strong heritage, negatively influenced the pressure and temperature limits of the cold helium system. For example, the Space Shuttle helium system was not designed for high temperatures, therefore the helium temperature max design case for this experiment was tied to the Space Shuttle limit, rather than pushing a performance boundary for the HEX, prop tank, etc. The goals of this experiment, though, could be met using these available hardware components so this route was chosen to minimize costs.

A regulation and isolation panel was installed downstream of the HEX. After an inline filter, the helium flow was split into parallel LOX and Methane pressurization legs consisting of (in order) an isolation valve, regulator, relief valve, and check valve (Figure 7). Downstream of the final check valve, each pressurization leg was plumbed into the existing Morpheus vehicle helium fill systems. Peak inlet pressure for the regulation panel was 3,600 psi, and outlet pressure for both legs was quasi-stable at $285 \mathrm{psig}$. The pressure loss in the plumbing between the regulator and propellant tanks varied with throttle level due to the change in helium flowrate. Since the regulator referenced its outlet pressure, not the tank pressure, the tank pressure also varied a few psi with throttle level.

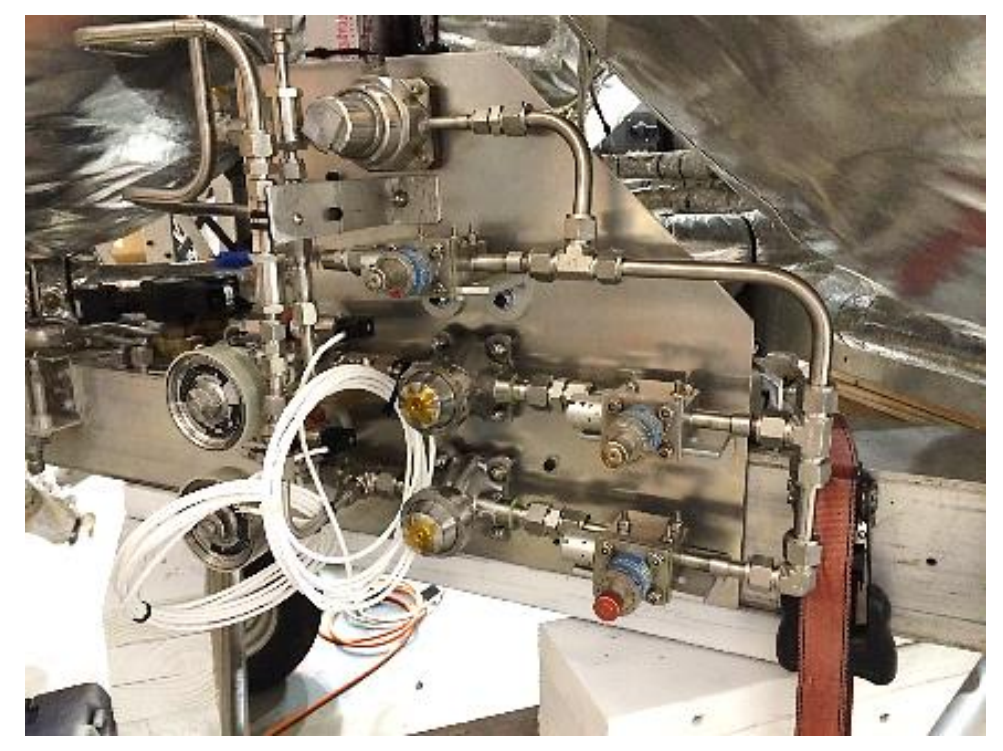

Figure 7: Helium system regulation and isolation components installed in the integrated test bed.

A pneumatic model was built using EASY5 to predict both steady-state and transient operating characteristics of the pressurization system. It encompassed the high-pressure storage vessel, the propellant tank ullage volume, and all interconnecting lines and components. Heat transfer correlations were included to predict temperature blowdown in the COPV, ullage collapse in the propellant tank, and heat transfer from lines and components to/from the helium gas. This model was used to determine appropriate initial test conditions, specifically for the propellant tank ullage pressures, which significantly 
impact the initial transient flow rate of pressurant into the tanks. It was also used in the HEX component design to determine bounds on helium mass flow rate for different throttle profiles.

\section{High vs Low Pressure HEX}

The design strategy for the HEX pressure level required an integrated system analysis approach. For this implementation, a HEX was installed on the high pressure side of the helium system for a number of reasons. A notable benefit of this configuration was minimizing the need for costly high pressure cryogenic helium components (regulators, valves, etc). Of notable importance to a throttling lander-type application; since the HEX is inherently a high pressure drop component, placing it upstream of the regulators reduces the tank pressure swings that will occur with throttling and stored helium temperature loss due to expansion. In a low pressure configuration, these variations directly impact the tank pressure and complicate system performance. A low pressure version of the system tested could experience $>50$ psi tank $\Delta \mathrm{P}$ during throttling.

Another advantage to this configuration is reduced overall HEX size for a given heat load with smaller HEX internal channel sizing due to the lower volumetric flowrate. The high pressure HEX will experience higher wall stresses, but the smaller internal channels offset some of this effect.

A perceived disadvantage of the high pressure HEX is a more complicated design process or lower margins due to the higher pressures. There was no point in the design process at which the high pressure HEX was markedly more complex than a low pressure HEX. The same process could have produced either HEX with essentially equivalent effort. In either design approach, heat flux, wall stress, manufacturability, and temperature limits must be balanced. Yet, sufficient configuration variables existed such that the internal pressure was not a significant design limitation. Those variables included channel velocity, pressure drop, wall temp, channel shape, manufacturing process, materials, wall thickness, etc. A substantial variable available but not utilized was changing the input heat flux by moving the HEX location in the nozzle.

Note: Increased fatigue and creep impacts for the high pressure design were not assessed in this design process. For short duration missions with few cycles these may not be of concern, and the system would likely not be continuously pressurized for long durations.

Lastly, a high pressure HEX directly coupled to the high pressure storage tank typically reduces the overall pneumatic system part count compared to a low pressure HEX system.

\section{Instrumentation}

In addition to the existing vehicle instrumentation suite included for the former Morpheus project, the vehicle was augmented with additional instrumentation to measure the integrated performance of the helium pressurization system. A National Instruments CRIO data acquisition system was added to handle the additional sensors, and critical system data was split between the C-RIO and flight computer. 
Pressure sensors were placed at numerous locations in the helium system and between the propellant tanks to measure the repress system performance. The helium COPV was equipped with six grounded-tip Type $\mathrm{T}$ thermocouples to measure the axial distribution of helium temperature within the tank, and an additional five thin film thermocouples to measure the external temperature of the COPV. Helium mass flow was interpreted using the P-V-T method with a volume averaged temperature.

The main engine HEX used eight welded-on Type K thermocouples to measure the HEX hotwall and body temperatures and provide real-time health data. HEX inlet and outlet gas conditions were measured with exposed-tip Type K thermocouples and pressure sensors.

Additional exposed-tip Type $\mathrm{K}$ thermocouples measured the helium temperature leaving the helium regulators. Each of the four vehicle propellant tanks was augmented with an evenly-distributed centerline rake of six exposed-tip Type $\mathrm{T}$ thermocouples to measure the ullage gas axial temperature distribution during active repressurization. Additionally, each propellant tank had an even distribution of six external thin-film Type T surface thermocouples.

Lastly, three exposed-tip 14 gauge Type K thermocouples supported by tungsten bars measured the engine nozzle hot-gas boundary layer at the exit plane of the engine-mounted HEX.

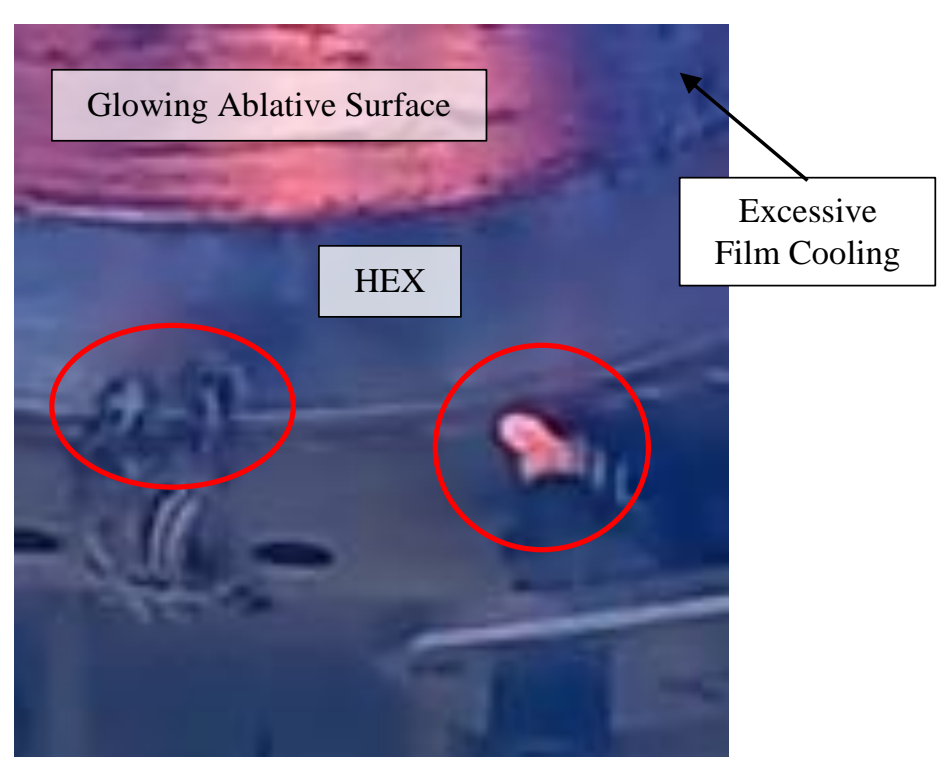

Figure 8: Nozzle exit and heat exchanger during hotfire, showing HEX hotwall bottom lip and hot gas boundary layer thermocouples

\section{Hotfire Test Operations and Commentary}

Hotfire tests were performed at NASA Johnson Space Center in the same location as Morpheus vehicle hotfire and tethered flight testing in 2011-2013. In this location, the vehicle was suspended $\sim 18$ ' above the ground and restrained with chains. The fueled vehicle weighed more than the engine max thrust, so thrust/weight did not exceed 1. A 50' cable tray was positioned between the ground servicing equipment and vehicle, facilitating helium loading and LN2 supply to the vehicle (for COPV and flight computer) when in the elevated position. Propellants were loaded on the ground prior to lift.

Fifteen (15) successful hot-fire tests were completed during the test campaign over five hot-fire test days, covering a range of objectives. Operation of the system was conducted at varying test durations, culminating with a $60 \mathrm{sec}$ duration test. Main engine throttling 
without chug was demonstrated down to $20 \%$ (5:1 throttling) through numerous intermediate throttle steps. Lower throttle steps down to $6 \%$ thrust were demonstrated, but chug-like pressure oscillations were recorded around 15\% that subsequently cleared below the $10 \%$ throttle step (note that SSC testing also showed chug at $\sim 15 \%$ throttle).

The HEX worked as designed, producing helium within the design outlet temperature range without overheating the hot wall at all engine throttle levels. Helium mass flow through the HEX varied passively with engine throttle level as propellant was drawn from the propellant tanks. Engine nozzle heat flux also varied with throttle level, so the HEX was designed to balance both transients. Test data shows the reduction in helium mass flow due to throttling was outpaced by the reduction in nozzle heat flux, resulting in an overall reduction in both HEX hotwall and outlet temperatures at lower throttle levels.

As a bonus data-gathering opportunity, engineers from the NASA Jet Propulsion Laboratory performed a plume impingement experiment under the vehicle during a portion of these hotfire tests. A rake of thermocouples and pressure sensors were anchored to the pavement under the vehicle and covered in a Mars soil simulant. Plume impingement pressures and temperatures were recorded with a remote subterranean data system during four hotfire tests that included main engine throttling and two different vehicle elevations. Soil exit velocities were measured using several down and side facing cameras. This test was a repeat of a similar experiment using the Morpheus vehicle in 2013.

\section{Helium and Propellant Loading}

A dry run and two operational wet runs provided the opportunity to optimize the high pressure helium loading method. Ground loading of the helium COPV was conducted in two phases. First, a low-pressure load to $~ 1,200$ psi (with active LN2 cooling) was conducted from a 3,500 psig tube trailer, resulting in $\sim 3.5 \mathrm{lbm}$ of helium loaded in the COPV at $<-250 \mathrm{~F}$. Compressive heating of the helium was initially a concern, but correct timing of the LN2 jacket and helium fill operations prevented both pulling a vacuum on or overheating the COPV. The 1,200 psi intermediate pressure was the personnel exposure limit for the COPV at cryogenic temperatures, defined by the zero-load pressure of the COPV composite overwrap (the pressure at which the composite overwrap of the COPV begins to experience tensile loading). Leak checks and trouble-shooting were conducted at this pressure as well as manual LO2 and LCH4 propellant loading operations.

The second step of COPV loading increased pressure to 3,600 psig from an array of 6,000 psig helium bottles that were remotely-controlled after personnel were cleared from the test pad area. Tank pressurization occurred rapidly but once reaching a steady state pressure transitioned to a trickle flowrate as the helium cooled and drew in more mass. Over both loading steps, $\sim 1.5$ hours was required to load the target $8.8 \mathrm{lb}$ of helium. Shortly before hotfire operations, the propellant tanks were pressurized using helium from a tube trailer to 280 psig (a few psi lower than the cold helium system pressure regulators).

The cooling jacket on the COPV drew LN2 from a ground-based dewar, up the cable tray to the vehicle. A cryo solenoid valve maintained COPV temperature using one or more skin temp thermocouples and a ground software based PWM controller. Approximately 
$50 \mathrm{lb}$ of LN2 was required for the initial chill-in of the COPV and helium gas. Once fully chilled, steady state heat leak into the helium was $\sim 64$ watts, necessitating $\sim 12 \mathrm{lb} / \mathrm{hr}$ LN2 for cooling and delivery system inefficiencies. On test day, the LN2 flow was frequently overdriven to the point of LN2 dripping out of the COPV jacket in order to more rapidly chill the tank between tests.

\section{HEX and Hot gas performance}

Maximum hotwall temperatures of the Inconel HEX were $350{ }^{\circ} \mathrm{F}$ at the $20 \%$ throttle position, and less than $1,650{ }^{\circ} \mathrm{F}$ at $100 \%$ throttle (Figure 9). Helium HEX gas $\Delta \mathrm{T}$ (outletinlet temperature) at steady flow conditions ranged from $325^{\circ} \mathrm{F}$ at full throttle to $150^{\circ} \mathrm{F}$ at $20 \%$ throttle. Data shows that the heat flux measured from the helium data is slightly less than the water flow calorimeter data from SSC (Figure 4), as expected by the higher cooling capacity of the water flow and higher overall thermal resistance of the thicker-wall helium HEX relative to the water calorimeter. The pressure drop for the HEX ranged from 20 psid at $20 \%$ throttle to 65 psid at $100 \%$ throttle (steady-state).

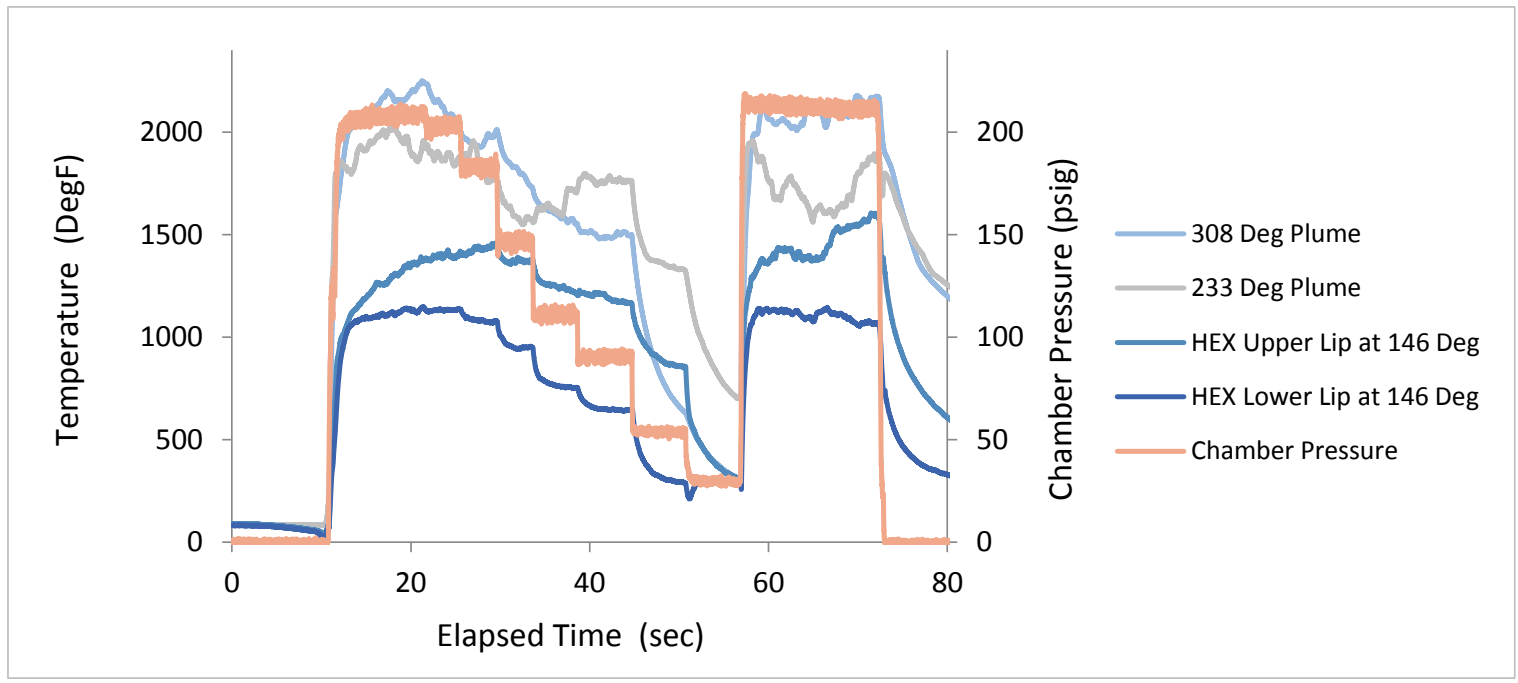

Figure 9: Typical HEX hotwall and nozzle plume temperatures during a deep throttling hotfire test - note the plume separation at 50 psi

One composite overwrapped Sil-Phen ${ }^{9}$. ablative chamber was used for the 15 cold helium hotfire tests at JSC and 10 development hotfire tests at SSC, accumulating 338 seconds life. Over this period the throat area increased 5.0\% due to erosion but the nozzle exit diameter did not appreciably increase in size. The HEX may have provided cooling and support structure at the ablative/HEX interface, minimizing erosion at that location. The ablative liner has not yet been sectioned for char depth analysis. 


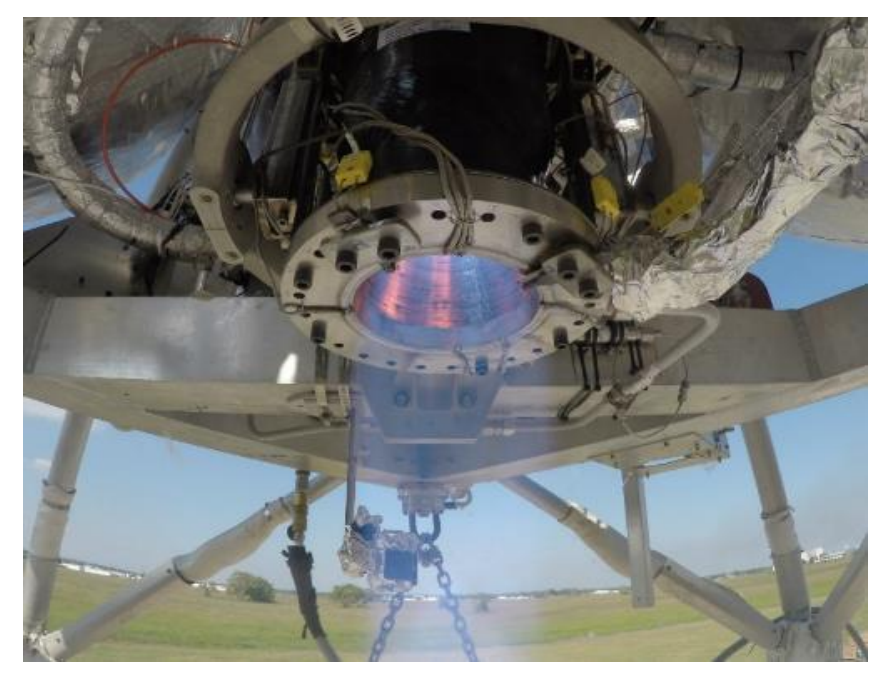

Figure 10: Steady state operation of the HEX installed on the vehicle main engine.
Streaking in the nozzle plume is apparent in Figure 10 - this was caused by unfortunate excessive film cooling at the injector in several circumferential locations.

HEX hotwall thermocouples and repositionable hot gas boundary layer thermocouples facilitated direct measurements of these hot and cold streaks. Based on this data and the engine performance model, it is estimated that the excessive film cooling reduced the available heat flux at the nozzle exit by 0.3 BTU/in ${ }^{2}$-s.

Hot-gas boundary layer probe thermocouples generally agreed with the HEX hot wall welded thermocouples and the predicted adiabatic wall temperature. The effect of high film cooling flow can be seen in Figure 11, with boundary layer temperature variation for the three different types of streaks observed and a HEX hotwall thermocouple at the 146 degree position that was in the same warm streak as the 158 degree position probe. Hot and warm streaks comprised $\sim 70 \%$ of the nozzle circumference. One probe burned through shortly into hotfire 14, suggesting transient proximity to core combustion gases.

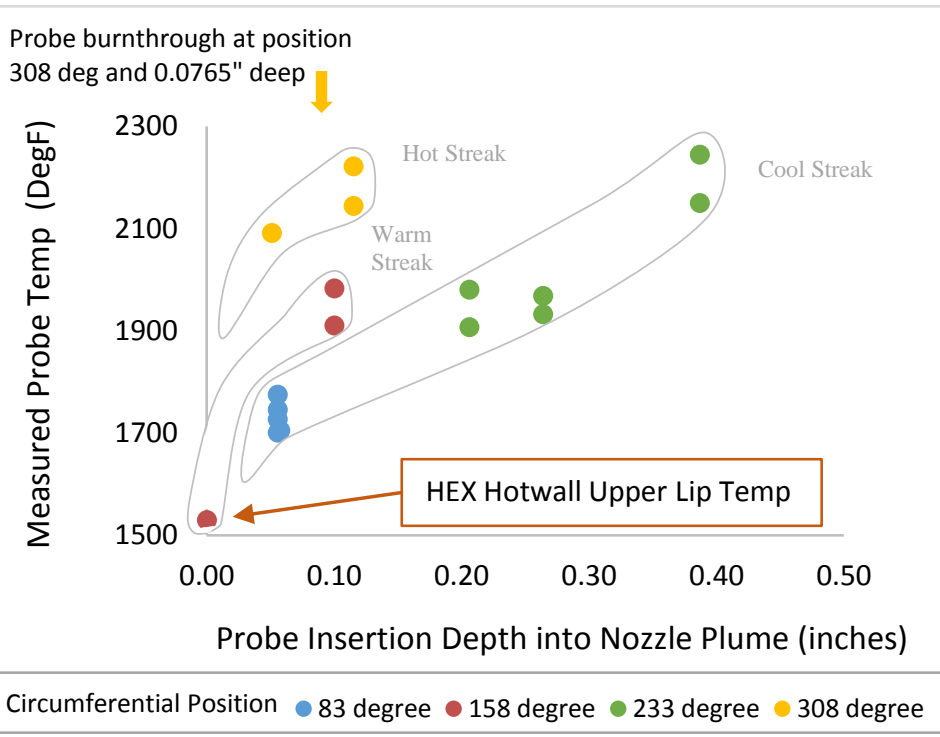

Figure 11: Nozzle hot gas and HEX hot wall temperatures for hotfires 10-15 indicating circumferential and boundary layer heat profiles.

\section{Helium System Performance}

The COPV helium inlet/outlet was located at the top of the tank. The tank inlet was not built with a diffuser so the incoming helium resulted in a notable stirring of the ullage gas during rapid loading. Stratified temperature layers formed relatively quickly during both quiescent timeframes and the trickle-fill stage of helium loading. Thermocouple rakes in the helium COPV show a relatively small amount of stratification in the bulk volume of the tank and out of family conditions in the tank bosses. During hot-fire usage, the COPV temperature drop was relatively consistent across all temperatures on the rake (Figure 12). 

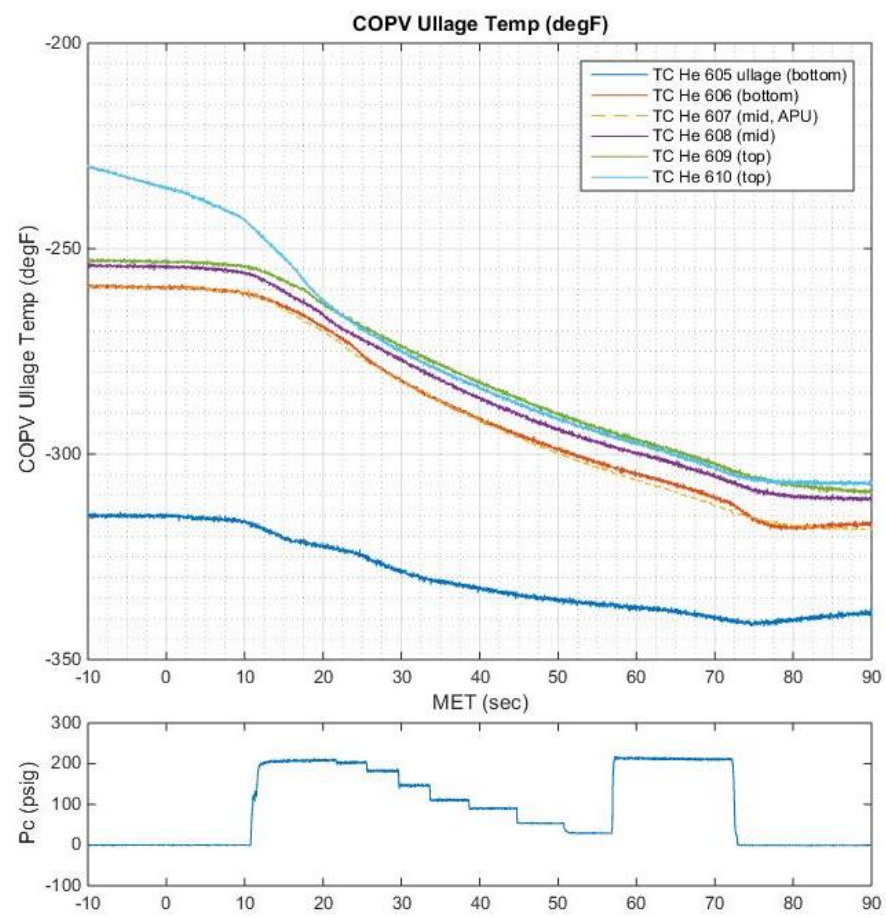

Figure 12: COPV Gas temperatures during a typical hotfiring with typical stratification. The tip of the probe is most likely contacting the bottom tank boss and is indicating LN2 present in the cooling shroud pretest.
The nominal propellant tank fill level for this series of tests was $\sim 25 \%$ liquid, resulting in large ullage volumes at the start of each test. Thermocouple rakes in the propellant tank ullage gas show a strong amount of stratification prior to each hotfire, with only minor changes during active hotfire pressurization, as shown in Figure 13 (the exposed tip thermocouples had a fast enough response time to see wind events inside the tank, if present at the tank centerline). External skin thermocouples show a similar response, albeit dulled by the tank wall thermal mass.
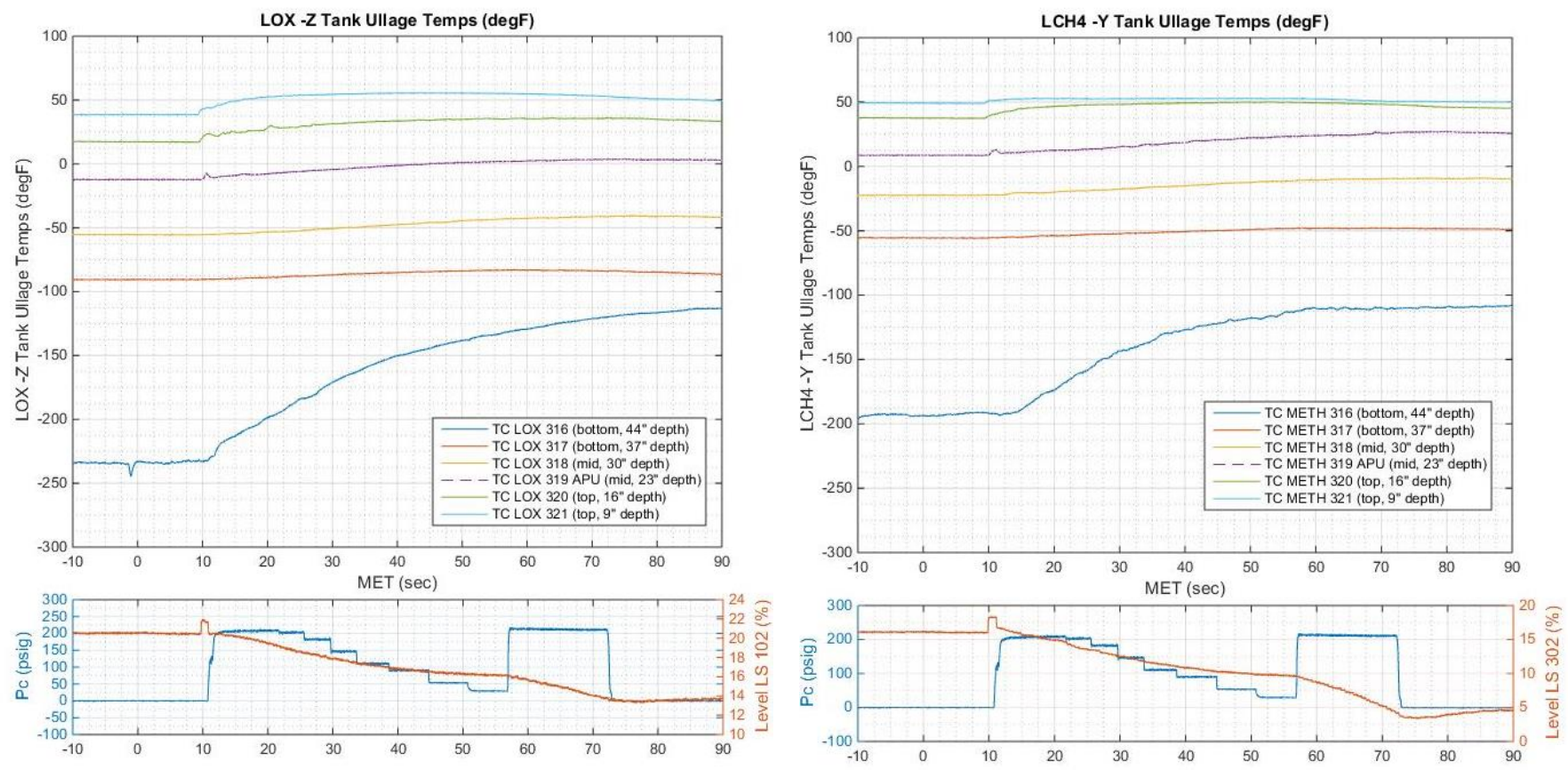

Figure 13: Example LOX and Methane tank ullage temperatures during a long duration hotfire 
The propellant tanks did not use a diffuser at the helium injection location, but perpendicular helium injection into the cylindrical upper tank boss (Figure 14) may have arrested much of the injection velocity, reducing pressurant mixing into the large ullage volume (based on preliminary CFD analysis of this design). Additionally, the upper tank walls were relatively warm during these tests due to the stratification and low liquid volume, providing a benign environment to the incoming warm helium.

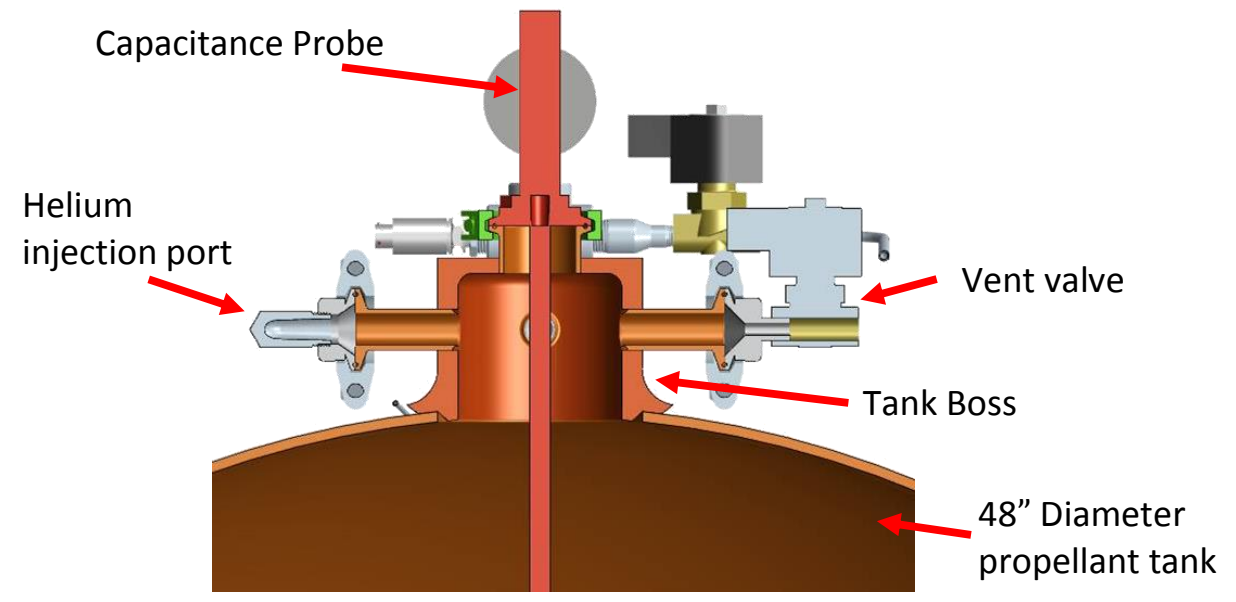

Figure 14: Propellant tank boss hardware

Future testing of this integrated cold helium repress system (expected in 2016) will expand the test cases to include 50-98\% full propellant tanks and longer main engine hotfire durations. During this test series increased ullage mixing and a marked decrease in pressurization efficiency are expected.

\section{Ignition Transient and Steady State Pressurization}

Prior to the main engine ignition sequence, the propellant tanks were pressurized to 3-5 psi below the high pressure regulator outlet pressure to ensure positive flow through the system when the isolation valves were opened. After satisfying this constraint, the typical vehicle ignition process ${ }^{10}$ for the main engine begins with a 10 second pause for automated propellant chills, if necessary. At the end of the pause, a brief helium purge cleans the injector and igniter, followed by ignition of the gas-gas igniter and then main combustion chamber ignition.

Also at the end of the 10 second pause, the high pressure helium isolation valves on each pneumatic system leg opened, starting flow of cryogenic helium gas through the HEX, regulators, and into the propellant tanks. The 3-5 psi $\Delta \mathrm{P}$ initial condition was sufficient to ensure positive flow on demand without overchilling the high pressure circuit.

Figure 15 shows data from a 30 second test at $100 \%$ throttle. After ignition, the temperature rise across the heat exchanger does not reach a steady value until both LOX and Methane ullage volumes reach their pressure set points and the mass flow rate levels out. Once achieved, the steady state pressurant temperature rise through the heat exchanger is $300^{\circ} \mathrm{F}$. 


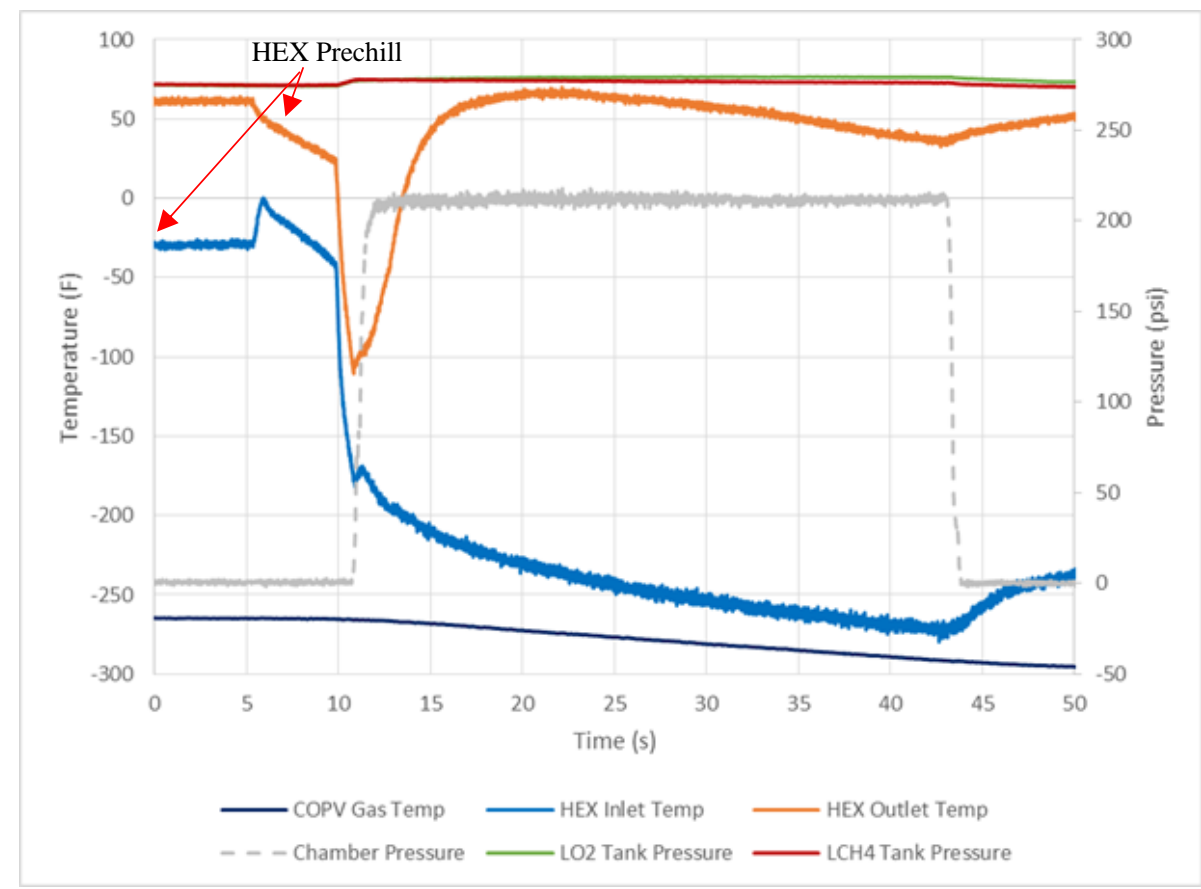

Figure 15: Pressurization system test data (steady-state test, 100\% throttle)

Later tests included multiple throttle steps to demonstrate system response to changing flow demand. In the test shown in Figure 16, for example, the initial ullage pressures were set 20 psi lower than the regulator set point, leading to higher than typical mass flow demand for much of the test. As a result, the temperature rise for the first 18 seconds of the test is well below the design point of the system, compared with the temperature rise observed in the final throttle step of the test at which point the helium volume inflow was equal to propellant volume outflow.

Below the $30 \%$ throttle point, a significant drop in HEX $\Delta \mathrm{T}$ was observed due to hot gas flow separation in the nozzle, with a detachment point above the HEX location (confirmed on nozzle video). As the engine throttles down, the tank pressure began to increase corresponding with lower volumetric flow (and pressure drop) through the lines and components downstream of the regulator. After throttling back up, the tank pressures began to drop again as the volumetric flow returned to a higher steady value. As a result, for a system with simple regulator pressure control using a throttling engine, tank pressure will vary as the pressurant flow adjusts to varying throttle levels unless the regulator is referenced to the tank pressure (with associated potential for imbalance) . This operating characteristic can be minimized by reducing the flow resistance between the regulator outlet and tank inlets.

This 2,000lbf engine utilizes a single throttle actuator for both main propellant valves. As a result, the engine mixture ratio is not directly controlled and rises a bit as the throttle level drops below 1,000lbf. This can be seen on the tank pressure trace. Initially, the tank pressures are equal due to the equal helium regulator settings. As the engine runs and propellant is drawn from the tanks, the pressures diverge to stable points and then return to a similar value as the engine throttles down and mixture ratio increases. 


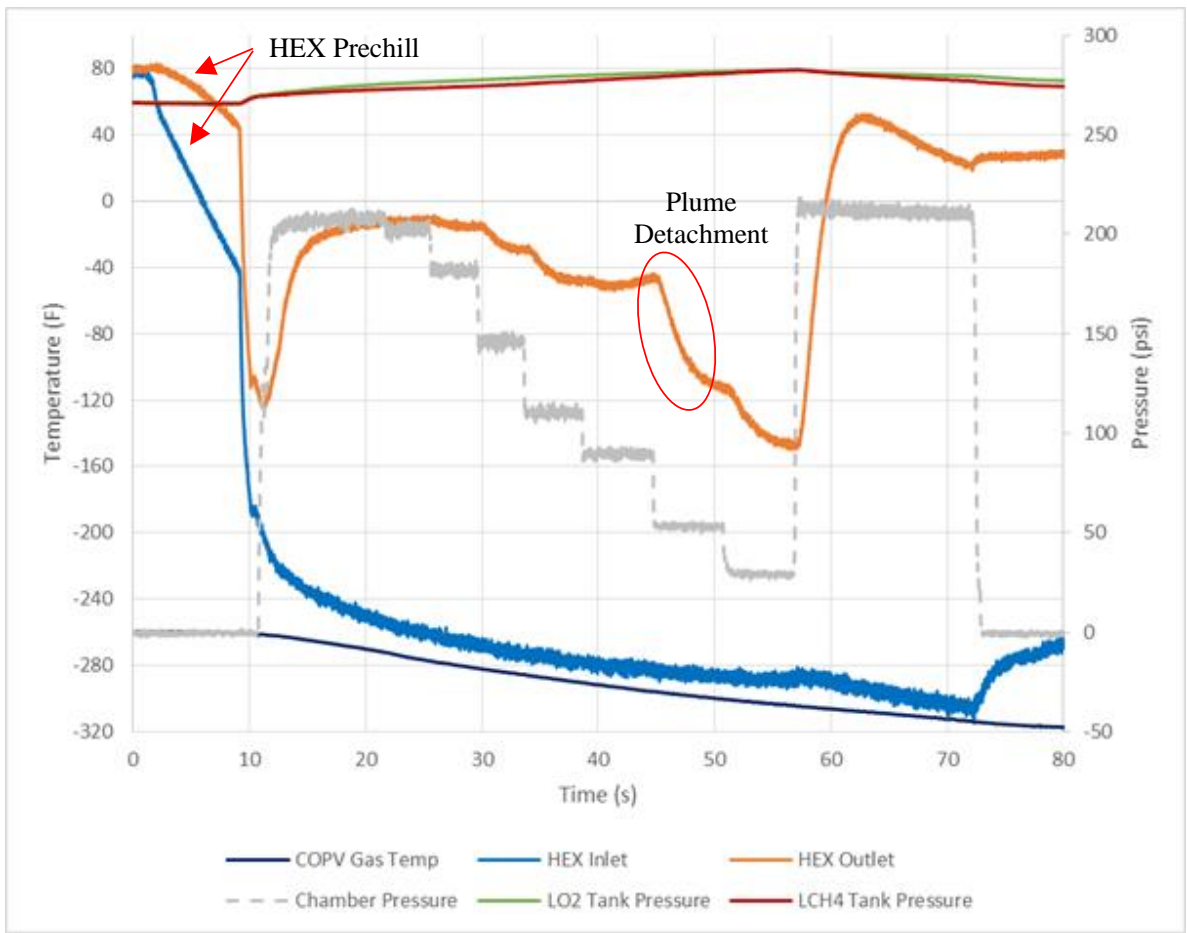

Figure 16: Pressurization system test data (Long duration test with throttling)

Early in the test series, the HEX was manually prechilled prior to the ignition sequence using a downstream dump valve to reduce the risk of HEX overheating during ignition (Figure 15). Increasing confidence in the system facilitated reducing the prechill requirement, and later in the test series the prechill was performed through automated sequencing during the $10 \mathrm{sec}$ pre-ignition pause (Figure 16), although analysis suggests the HEX prechill was not needed.

Based on system data collected during testing, models suggest the HEX does not require the strong cooling event during ignition caused by opening the high pressure helium isolation valves (thereby pressurizing the propellant tanks for the last few psi and causing high helium flow through the system). System transient models indicate that the HEX would not overheat if the tanks and regulators were at equal pressure prior to ignition. In the equal pressure state, the helium flow would grow proportionally with rising propellant draw during the ignition sequence and the HEX outlet temperature should not exceed the system design limit. If the tank pressures were higher than the regulator setting at ignition, though, the HEX would operate uncooled for some period of time and would likely overheat or require a refractory metal to avoid damage. In this situation, the downstream pneumatic components could be subjected to very high

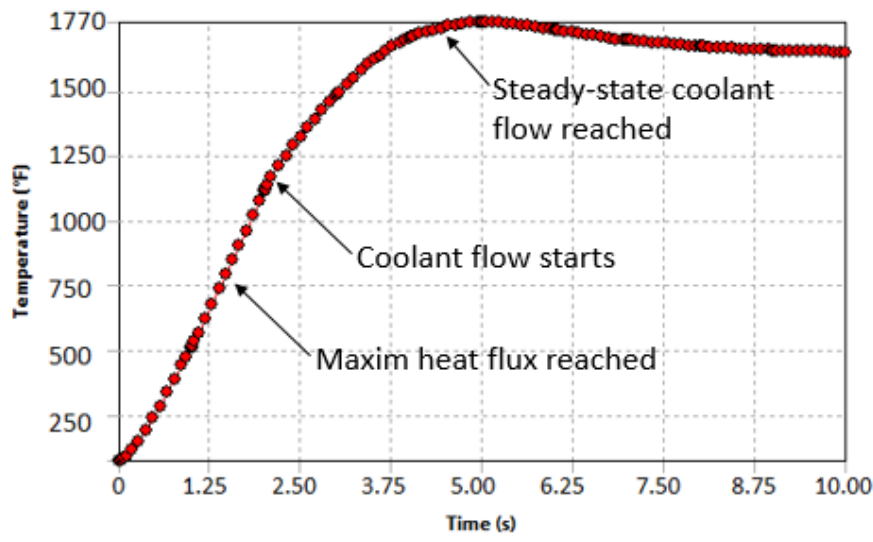

Figure 17: Transient thermal FEA results with late onset of helium flow 
HEX outlet temperatures when repress flow finally begins if the system thermal mass is not high enough to absorb the transient overheating.

An example case with late helium flow initiation is shown in Figure 17 (FEA model output), with helium flow starting after engine ignition and acceptable peak temperatures.

\section{Pressurization System Performance Metrics}

A direct metric for measuring the performance improvement enabled by a cold helium pressurization system is comparing the overall spacecraft dry mass with a cold helium system to one with an ambient helium system. This metric takes into account the mass reduction as a result of smaller high pressure storage tanks and also any mass additions such as the HEX and helium conditioning hardware.

The COPV tested on the former Morpheus vehicle, with a maximum system pressure of $3700 \mathrm{psig}$, can store $4.2 \mathrm{lbm}$ of Helium at $68^{\circ} \mathrm{F}$. The same COPV and system can store $9.9 \mathrm{lbm}$ of Helium at $-275^{\circ} \mathrm{F}$. To quantify how this storage method improves Morpheus vehicle mission performance, the installed pressurization system design with demonstrated component masses was scaled up to include enough helium storage to completely drain fully-loaded propellant tanks. This analysis was accomplished for both cold and ambient helium storage configurations using the same tank performance factor and additional masses for structure, plumbing, and insulation/cooling. The resulting COPV volume requirement was $5.8 \mathrm{ft}^{3}$ for the cold storage configuration and $12.8 \mathrm{ft}^{3}$ for the ambient storage configuration, translating into an overall vehicle dry mass reduction of roughly 78 lbm from an ambient to cold helium system. A similar but more detailed trade was performed for the MARE spacecraft design ${ }^{4}$, resulting in a $66 \mathrm{lbm}$ dry mass reduction versus an ambient storage system. This resulted in a large improvement in useful payload mass for this small science mission (approximately 40\%).

Another way to quantify the effectiveness of pressurization systems, especially with cryogenic propellants, is the collapse factor ${ }^{11}{ }^{12}, C F$, which is an efficiency term that relates the actual mass of pressurant required to the ideal mass required for a no-heattransfer scenario. Helium used to maintain tank pressure will collapse in specific volume over time as the injected helium cools due to the cryogenic tank environment, thereby requiring a higher mass flow to maintain a constant tank pressure than would be needed for solely propellant volume replacement.

$$
C F_{i}=\frac{\dot{m}_{\text {Pressurant, actual }}}{\dot{m}_{\text {Pressurant, ideal }}} \approx \frac{\dot{V}_{\text {Pressurant }}}{\dot{V}_{\text {Propellant }}} \quad \text { (1) } \quad C F_{C}=\frac{\text { Total Mass } \text { Pressurant, actual }_{\text {Total Mass }} \text { Pressurant, ideal }}{\text { Tot }}
$$

The term is typically used in two ways: an instantaneous collapse factor relating the actual mass flow rate to the ideal mass flow rate, and a cumulative collapse factor relating the actual total mass required to ideal total mass required for a mission. The instantaneous value, $C F_{i}$, of Eqn (1) is useful for understanding the bounding flow rates for pressurization system component and heat exchanger design under various operating conditions - and is nearly the same as the pressurant/propellant volume flowrate ratio, which may be easier to 
use for quick assessments. A cumulative collapse factor, $C F_{c}$, of Eqn (2) accounts for all pressurization inefficiencies over the course of a mission (initial tank pressurization, expulsion, coast phases, etc) is more useful for comparing different spacecraft systems.

In an ideal scenario, with an adiabatic barrier between the entering pressurant and tank ullage space, $C F_{i}=1$. In reality, energy loss from the pressurant to the cooler ullage gases, tank wall, propellant, etc. through convection and diffusion will result in more pressurant required than the ideal case. $C F_{i}$ is influenced strongly by ullage gas mixing, placing an emphasis on diffuser design and floating a hot helium layer over the existing cooler helium and propellant vapor ullage gases. This ratio is also a function of helium pressurant inlet temperature, tank ullage volume, propellant consumption, ullage cooling by tank structure, etc. Helium pressurant inlet temperature is a function of many upstream components by adding heat actively (HEX) or adding/subtracting heat passively through the latent heat and thermal mass of these components and the spacecraft environment (hot LEO or cold deep space conditions). Generally, the $C F_{i}$ value will decrease as the ullage volume becomes stratified since this helps to reduce heat transfer and mixing between the relatively warm entering pressurant and the colder portions of tank wall and ullage gas near the liquid surface. For missions requiring multiple burns, $C F_{i}$ will increase during coast phases since stratified layers and ullage heat will be lost during zero-g timeframes. Thus $C F_{C}$ is the more important metric for vehicle to vehicle comparison since it considers all events over the course of a mission that impact system performance.

For this series of hotfire testing, the ullage volume fraction for each test was approximately $75 \%$, with significant ullage stratification at the start of each test. Additionally, the upper tank walls near the helium inlets were at ambient temperature, resulting in minimal heat transfer to the entering pressurant gas. In these low heat loss scenarios, the measured $C F_{i}$ pressurization efficiency factor for steady-state segments of testing approaches 1 within the bounds of experimental uncertainty. Future tests will be performed with smaller ullage volumes to quantify how these small volumes, colder ullage temperatures, and higher heat transfer rates impact $C F_{i}$ and $C F_{c}$.

As cryogenic spacecraft with pressurization systems are designed with increasing frequency, these terms will be useful metrics to compare systems, help predict weight and cost during the design phase, or help diagnose trouble spots on an existing system.

\section{System Improvements and Future Testing}

The prime control variables for maximizing the benefit of a cold helium system are minimizing helium storage temperature, maximizing the high temperature capability of the pressurization system, and effective diffuser design to minimize pressurant energy loss.

For future designs, it will be critical to develop a thermal control strategy that limits the ability of the stored helium to receive heat loads (solar radiation, heat soakback, etc). For hot helium usage, limiting factors might include propellant tank temperature limits, 
component softgood temperature limits, diffuser performance, as well as upper bounds on heat absorbed by the propellants. Additionally, a HEX material with higher thermal margin (refractory metal) could simplify ignition sequencing or generally improve HEX margins provided the downstream components (relatively close-coupled on a small spacecraft) can handle higher temperature transients. Lastly, efficiently pressurizing the initial propellant tank ullage (prior to engine operation) presents an added challenge for cold helium systems since the cryogenic helium has a very low specific volume and therefore strongly influences $C F_{c}$. The 5-10\% tank ullage volumes typically needed for systems with passive mechanical pressure regulators consume a large quantity of stored cryo helium during initial tank pressurization. This can be improved several ways, one of which is reducing or eliminating the initial ullage volume which provides the added benefit of reducing overall propellant tank size but could require active tank pressure control.

In the upcoming year, this cold helium system will be hotfire tested in the NASA Plum Brook B2 thermal vacuum chamber. Planned modifications to the system for this test series includes flow meters on the oxidizer and fuel legs of the pressurant system to provide more accurate flow rate data (as opposed to the P-V-T method used in this experiment), helium diffusers in the propellant tanks, a new HEX installed at the $\varepsilon=10$ location on a 100:1 main engine nozzle, and $100 \%$ increase in instrumentation on the system and vehicle. Hotfire tests will be performed with larger propellant loads (ullage volumes between 2-50\%) and in both ambient and cryogenic environments to demonstrate higher collapse factors with smaller ullage spaces and cold tank walls. These system and environmental updates will allow for more accurate determination of the instantaneous and cumulative collapse factors over a wider range of operating conditions.

Additionally, the cold shroud of the B2 thermal vacuum chamber will provide an opportunity to prechill the entire vehicle to deep space thermal conditions prior to a portion of the hotfire tests, eliminating the latent heat variable of the cold helium system. This should be the lowest efficiency test of the installed system and will provide useful performance envelope data for a future flight system.

\section{Summary}

A cold helium pressurization system was installed on an existing prototype lander vehicle with cryogenic propellants and hotfire tested to collect preliminary performance data. The testing to date demonstrated steady state propellant tank pressurization over the throttling range necessary for a lander. This initial test series did not stress the potential ullage collapse variable of pressurization system design. Active repressurization with nearly full propellant tanks or nearly empty tanks with cold walls should result in increased ullage mixing and a marked decrease in pressurization efficiency. Therefore the additional testing planned will help to bound the performance envelope of the installed system.

General design strategy for the HEX and overall system was presented and resulting vehicle performance was outlined. 
Hardware-based examples of the vehicle mass reduction benefits of a cold helium system were described. Additionally, the pressurization performance efficiency metric collapse factor, $C F_{i}$ and $C F_{C}$ were defined and will be expanded on in subsequent works.

Lastly, potential system design upgrades were recommended and an overview of planned thermal vacuum hotfire testing was outlined.

\section{Acknowledgments}

This work was funded by the NASA Johnson Space Center Propulsion and Power Division; Edgar Castro, Chief, and Bruce Manners, Deputy Chief. JSC Propulsion branch management is John Applewhite and John Brewer.

The authors greatly appreciate the interest and support of the former Morpheus design and operations team at JSC and SSC in facilitating the continued use of the vehicle hardware. The JSC team includes Jim Rice, Jenny Devolites, Jacob Collins, Ian Young, Randy Wade, Dave Swartwout, Tom Hoge, Fred Shetz, Christina Deoja, Jason Graika, Steve Daniels, Frank Zapata, and intern Joshua Woods. Additionally, special thanks to Scott Holland and Harold Robertson for test day photography.

SSC test operations were provided by Andrew Guymon, Craig Chandler, Byron Bordelon, Aaron Head, Chuck Thurman, Melissa Huggins, Todd Meitzler, Jared Grover, Stephen Rawls, Bridget Jones, Aster Pastoral, Truc Le, Gerald "Butch” Howard, Patrick Guidry, Peter Tran, Tom Wolfe, John Searles, Sean Herring, and Derek Zacher.

We also appreciate the interest and patience of the JPL team in teaming with our operations to perform the Mars soil plume impingement tests: Jim Lewis, Tom Reynoso, Alexander Wolpe, David Vaughan.

\section{References}

\footnotetext{
${ }^{1}$ Hammock, W., Currie E., Fisher A., “Apollo Experience Report-Descent Propulsion System” National Aeronautics and Space Administration, March 1973

2 "Saturn 5 Launch Vehicle Flight Evaluation Report AS-503, Apollo 8 Mission", NASA Marshall Space Flight Center, 1969

${ }^{3}$ Olansen, J.B., Munday, S.R., and Devolites, J.L., "Project Morpheus: Lander Technology Development" AIAA-2014-4314, AIAA SPACE 2014 Conference and Exposition, San Diego, CA, August 2014.

${ }^{4}$ Hurlbert, E., Morehead, R., Melcher, J., Atwell, M., "Integrated Pressure-Fed Liquid Oxygen / Methane Propulsion Systems - Morpheus Experience, MARE, and Future Applications”, 52 ${ }^{\text {nd }}$ AIAA/SAE/ASEE Joint Propulsion Conference, 25 Jul - 27 Jul 2016, Salt Lake City, UT, United States.
} 
${ }^{5}$ Ray, D., Greene, N., Revilock, D., Sneddon, K., Anselmo, E, "High Pressure Composite Overwrapped Pressure Vessel (COPV) Development Tests at Cryogenic Temperatures", $49^{\text {th }}$

AIAA/ASME/ASCE/AHS/ASC Structures, Structural Dynamics, and Materials Conference, 2008

${ }^{6}$ R. Jimenez, S. Flores, K. Romig, E. Hurlbert, —Characterization of a Thermodynamic Vent System (TVS) for an On Orbit Cryogenic Reaction Control Engine (RCE) Feed System, , 44thAIAA-ASME-SAEASEE Joint Propulsion Conference 2008

${ }^{7}$ Melcher, J., Morehead, R., Atwell, M., and Hurlbert, E., "Design and Test of a Liquid Oxygen / Liquid Methane Thruster with Cold Helium Pressurization Heat Exchanger", JANNAF 62nd Joint Propulsion Meeting, Nashville, TN, June 2015.

${ }^{8}$ Ring, E. ed., "Rocket Propellant and Pressurization Systems", Prentice-Hall Inc, Englewood Cliffs, NJ, 1964

${ }^{9}$ Richter, G., Smith, T., "Ablative Material Testing for Low-Pressure, Low-Cost Rocket Engines"

JANNAF $32^{\text {nd }}$ Combustion Subcommittee Meeting, Huntsville AL, 1995

${ }^{10}$ Melcher, J., Morehead, R., "Combustion Stability Characteristics of the Project Morpheus Liquid Oxygen / Liquid Methane Main Engine" 50th AIAA/ASME/SAE/ASEE Joint Propulsion Conference July 28-30, 2014, Cleveland, OH AIAA 2014-3681

${ }^{11}$ Stochl, R., Maloy, J., Masters, P., DeWitt, R., "Gaseous Helium Requirements for the Discharge od Liquid Hydrogen From A 1.52 Meter Diameter Spherical Tank", NASA Technical Note TN D-5621, 1970

${ }^{12}$ Quay, L., Hodge, B., “A History of Collapse Factor Modeling and Empirical Data for Cryogenic Propellant Tanks," 46th AIAA/ASME/SAE/ASEE Joint Propulsion Conference \& Exhibit, Joint Propulsion Conferences,AIAA2010-6559 